\title{
«Mort n'espargne ne petit ne grant». Études autour de la mort et de ses représentations
}

\section{Maria Colombo Timelli}

\section{(2) OpenEdition}

1 Journals

\section{Édition électronique}

URL : https://journals.openedition.org/studifrancesi/43549

DOI : 10.4000/studifrancesi.43549

ISSN : 2421-5856

Éditeur

Rosenberg \& Sellier

\section{Édition imprimée}

Date de publication : 1 juin 2021

Pagination : 195-196

ISSN : 0039-2944

\section{Référence électronique}

Maria Colombo Timelli, « «Mort n'espargne ne petit ne grant». Études autour de la mort et de ses

représentations », Studi Francesi [En ligne], 193 (LXV | I) | 2021, mis en ligne le 01 juillet 2021, consulté

le 15 octobre 2022. URL : http://journals.openedition.org/studifrancesi/43549; DOI : https://doi.org/

10.4000/studifrancesi.43549

Ce document a été généré automatiquement le 15 octobre 2022.

\section{(c)}

Creative Commons - Attribution - Pas d'Utilisation Commerciale - Pas de Modification 4.0 International - CC BY-NC-ND 4.0

https://creativecommons.org/licenses/by-nc-nd/4.0/ 


\title{
«Mort n'espargne ne petit ne grant». Études autour de la mort et de ses représentations
}

\author{
Maria Colombo Timelli
}

\section{RÉFÉRENCE}

«Mort n'espargne ne petit ne grant». Études autour de la mort et de ses représentations. Actes du XVIII ${ }^{e}$ congrès international de l'association Danses macabres d'Europe, Paris, 19-23 mars 2019. Textes réunis par Il. HANS-COLLAS, D. JUGAN, D. QUÉRUEL, H. et B. UTZINGER, Paris, Éditions du Cherche-Lune, 2019, 527 pp.

Dans la trentaine de contributions qui composent ce beau recueil, et dont les sujets couvrent un espace aussi vaste que l'Europe et une diachronie allant du Moyen Âge au $\mathrm{xx}^{\mathrm{e}}$ siècle, un tri a été opéré: nous signalerons en particulier les articles portant sur la France médiévale au sens le plus large de cet adjectif.

Une première section est dédiée à la «Littérature médiévale». Gérard GROS (Au-delà de la mort ici-bas: les funérailles des chevaliers chrétiens dans la "Chanson de Roland", pp. 10-25) propose une analyse en deux volets des laisses consacrées à la mort d'olivier, Turpin, Roland dans la plus célèbre des Chansons. Est d'abord étudié le lexique utilisé pour évoquer l'agonie et la mort (falt li [à Turpin] le coer par exemple, puis gesir, finer), la sépulture et les obsèques (bieres, aitres de musters, martroi, carnel etc.). G.G. évoque ensuite l'itinéraire de Charlemagne vers Aix, ses étapes, avec un passage significatifs à Blaye, jusqu'à la mort d'Aude. Danielle Quéruel présente ensuite le contenu du Pas de la Mort, poème composé par Amé de Montgesoie entre 1457 et 1465 pour Isabelle de Bourbon. Si les œuvres consacrées à une réflexion sur la mort sont relativement nombreuses dans la Bourgogne $\mathrm{du} \mathrm{xv}^{\mathrm{e}}$ siècle, le Pas présente la particularité de s'appuyer sur une trame narrative en exploitant en même temps le jeu de l'allégorie ( $L e$ voyage de l'homme vers la mort: "Le Pas de la mort" d'Amé de Montgesoie, pp. 26-36). Dans un 
article complémentaire, Isabelle DELAUNAY examine le manuscrit du Pas qui appartient à la collection de Frank Boucquillon: executé vers 1500, il contient douze enluminures, œuvre de deux peintres qui ont souvent collaboré à Paris vers la fin du Xv siècle: le Maître d'Etienne Pouchet et le Maître des Entrées parisiennes ("Le Pas de la mort": un manuscrit enluminé à Paris vers 1500, pp. 37-42). S'intéressant aux «fictions épitaphiques» du Xve siècle, Helen SWIFT entend s'opposer à la lecture qui voit dans les textes de René d'Anjou, Olivier de La Marche et Octovien de Saint-Gelais le désir d'une stabilisation de la mémoire, et propose plutôt de les interpréter comme autant de fictions évoquant «les apories de la mémorialisation: l'incohérence, le désordre, l'incertitude, l'énigme» (L'architecture funèbre dans la littérature du $\mathrm{Xv}^{\mathrm{e}}$ siècle: la décomposition mémoriale, pp. 44-56, cit. p. 46).

Dans la section consacrée aux «Pratiques funéraires médiévales», signalons l'essai de Marco PICCAT, qui s'intéresse à la légende et aux représentations murales, parfois rattachées à une Danse macabre, dédiées à Pierre de Luxembourg dès le XIV ${ }^{\mathrm{e}}$ siècle dans différentes chapelles en Provence et au Piémont («Après laquelle odeur et flaireur, tous les petis enfans... courroient par les rues...»: la vie et les miracles de Pierre de Luxembourg (1369-1387), pp. 94-111).

4 L'imprimerie offrit aux sujets macabres de nouvelles voies de diffusion (troisième partie: «Danses macabres imprimées et gravées»). Hélène Colleu s'interroge sur la publication par Guy Marchant d'une Chorea ab eximio Macabro en 1490, à savoir cinq ans après sa princeps en français; elle situe cette version «savante» dans le cadre du bilinguisme de l'époque et dans la production de Marchant, et en analyse les techniques de traduction ("Chorea ab Eximio Macabro": appropriation, traduction et diffusion d'un thème macabre, pp.114-131). C'est en revanche aux illustrations «macabres» fournies par Thielman Kerver, allemand d'origine devenu imprimeur à Paris, que s'intéresse Thierry CLAERR (L'image de la mort dans l'illustration des livres d'heures sortis des presses de Thielman Kerver, imprimeur libraire à Paris de 1497 à 1552: renouvellement iconographique?, pp.132-149). La tradition imprimée des livres d'heures est aussi le sujet de la contribution de Denis HüE, qui analyse les illustrations marginales souvent inspirées à la Danse macabre dans les Heures publiées par Gillet Hardouyn en 1512, accompagnées des Figures de la vie de l'homme (Les "Figures de la vie de l'homme" de Gillet Hardouyn, pp. 150-173; en annexe, texte des Figures selon l'édition Hardouyn de 1514, et Accidens de l'homme tiré des Heures à l'usage de Sens, Simon Vostre, 1513).

5 Les Danses macabres monumentales peuvent aussi intéresser nos lecteurs, dans la mesure où les deux manifestations - littéraire et artistique - sont intimement liées. Didier JUGAN essaie de «dépouiller» la Danse Macabre des éléments factices qui s'y sont ajoutés au fil du temps afin de revenier à l'«original» du cimetière des Saints-Innocents ; celuici dériverait à son tour d'un modèle iconographique d'origine allemande. S'y ajoute l'analyse d'un rôlet de théâtre du début $d u \mathrm{Xv}^{\mathrm{e}}$ siècle ( $\mathrm{AD}$ de Chambéry) où sont transcrites les répliques de «mort» (Déconstruction d'une Danse macabre. Vers un modèle originel antérieur à 1424, pp.196-222). Rappelons aussi les contributions de Lannie RoLLiNs, sur la Danse macabre peinte sur le plafond de la collégiale Saint-Salvi à Albi (pp. 224-241) et de Cristina NoAcco, sur la célèbre Danse macabre de Pinzolo (pp. 242-266).

6 Ce beau volume, imprimé sur papier glacé et somptueusement illustré, se clôt avec un panoramique de Michel PASTOUREAU consacré aux Couleurs de la mort au Moyen Âge 
(pp. 515-527): des pages aussi denses que synthétiques nous apprennent que la mort médiévale est polychrome, selon un large éventail de possibilités qui ne peut que dérouter l'homme moderne mais qui répond à des raisons culturelles n'ayant que très peu à voir avec le réalisme. 